\title{
Undergraduates Writing Publishable Cases: The Trials, The Tribulations, And The Real-World Learning
}

\author{
Jason Smith, University of Washington, Bothell \\ Josh Edwards, University of Washington, Bothell \\ Patricia C. Kelley, (PKelley@uwb.edu), University of Washington, Bothell
}

\begin{abstract}
If given the chance, undergraduates have the ability to write excellent case studies worthy of being published. This essay describes the benefits, challenges, and process of undergraduate case writing.
\end{abstract}

\section{INTRODUCTION}

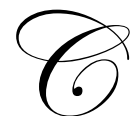

ase studies have been utilized as pedagogical tools in business schools for about a hundred years since Harvard Business School introduced them in the early 1900's. Early cases were based on field research and were used to study decisions in the functional areas of business (Naumes, W., Naumes, M., 1999). Today, case studies are used in countless universities worldwide and in many disciplines. Analyzing cases helps students to learn-by-doing. The students are provided information on a company and one or more business decisions that management must make. Students often conduct research on competitors and the industry environment, as would a company's decision maker to analyze and resolve the decision, thus simulating real world decision-making. Through this approach, students learn how to apply concepts, evaluate situations, formulate strategies, and resolve implementation problems (David, 2003). The process of using a case study can be difficult and time consuming for both graduate and undergraduate students because scenarios are rarely straightforward (see Appendix 1). However, there are obvious potential benefits for students with dedicated advisor involvement and student commitment. Although business students have benefited from analyzing case studies for years, the construction of the cases has predominantly been the job of professors and graduate students. While undergraduates have not traditionally been the writers of case studies, they could profit from this opportunity. This paper will demonstrate the advantages to undergraduates who write case studies and will outline the benefits, challenges, and process of undergraduate case writing.

\section{UNDERGRADUATE BENEFITS OF CASE WRITING}

Researching and writing a case enables the case authors to actively learn concepts by gathering data about a problem of organizational importance, framing that problem in a non-biased fashion, and analyzing the company and industry in order to develop solutions in a teaching note. A case writing project forces students to develop skills in several areas. These include reflecting on complex business environments, researching, learning methodologies, identifying problem scope, and applying business concepts to potential problem solutions. Writing a case requires extensive research to structure the information in a way that exposes issues, decisions, and behaviors (David, 2003). As a result of this thorough research, undergraduates can develop a much better knowledge about the topic, company, and industry compared to traditional class assignments. The research is not limited to the specific topic that the case is about. Often, there are other important elements that must be addressed in the case that might only superficially relate to the case topic. The knowledge that is gained by undergraduates is invaluable because it enables them to engage in a type of active learning generally reserved for graduate students. 
Through the extensive process of researching, writing, and editing a case study, undergraduates are able to improve their writing skills, build investigative research skills, and improve critical thinking and problem solving skills (Forman, H., 2006). As a result of the students' improvement in these areas, they can be more effective in school by having confidence and a better understanding of how to apply topics in an original way. Also, these skills will benefit future employers because they enable students to apply theoretical concepts in real world situations. Additionally, it can be beneficial for students to go through the publishing review process. They learn how to develop their work for publication, how to revise work for various audiences, and improve their business writing skill. If the case is published, other students will be encouraged to write cases or research papers, thus having a spillover effect on the business program and the students' colleagues. The final benefit of undergraduate case writing is to the reader of the published case. At the end of the project, the undergraduates will have a finished case that helps others learn the concepts discussed in the case and is written by those who know firsthand the challenges of undergraduate case analysis.

\section{UNDERGRADUATE CHALLENGES OF CASE WRITING}

There are many challenges that undergraduates face when writing a case. Coordination and communication issues are especially important in groups larger than two. Group members will likely need to set a time each week to discuss the progress of the case. By meeting weekly, the group can hold each other accountable to meeting deadlines, discussing challenges, and offering suggestions for improvement to other group members. If the case study is an independent study project for the student writers, it will be even more difficult to coordinate meeting times. Another potential challenge for undergraduates is overcoming different writing styles. It is crucial that the finished case study flows well and has one voice. Therefore, the editing process for undergraduate writers will be more strenuous than for graduate or faculty writers. To aid in this process, the advisor might periodically review the case and offer suggestions for improving the flow of the case.

When choosing to write a case, undergraduates should consider the amount of time that is required to complete it. Cases differ along several dimensions. They can be lengthy and complex or short and concise. The benefit for junior-year case writers is that they can negotiate with their faculty advisor a longer period of time in which to finish a lengthy case. This additional time for completion can help the junior case writer overcome the disadvantage of inexperience in case writing. The benefit of writing cases for a senior-year case writer is enhancing his or her skill set. However, if a student begins writing a case as a senior, he might not have enough time to finish a complex case using his newly acquired knowledge. Timing is an important element to consider when writing a case as an undergraduate.

\section{CASE DEVELOPMENT PROCESS}

Before undergraduates can begin the case writing process, they will need to have an advisor for the process. This position is best filled by a faculty member in the respective topic area, but can also include experienced individuals who are willing to contribute to the undergraduates' efforts. The role of the project advisor is to give direction to the writers, as well as contribute ideas and be a part of the student efforts. The advisor must also help the undergraduates form an outline of the learning objectives at the beginning of the project. Possible objectives might include learning about a specific management topic, learning about a specific industry, or learning about specific industry practices in organization design. If objectives are not outlined in the beginning, progress will be difficult to assess. Once such objectives are formed, writers can begin the process of research.

Undergraduate writers are usually unfamiliar with the development process of a case study. Undergraduates face unique problems such as the complexity of the case issues, inexperience with case analysis, and difficulties with writing (Mostert \& Mary, 2006). Undergraduates have a greater challenge when writing cases than professors or graduate students because of their lack of exposure to the business community and their lesserdeveloped writing skills. To overcome the challenge of linking concepts to real life problems, the advisor often needs to build in manageable steps for the undergraduate writers. These steps should be clearly expressed by the advisor so undergraduates have confidence about the direction of their research and writing progress. The steps can be incorporated into the Initial Detailed Teaching Note. 
In order for student writers to develop appropriate knowledge about the topic, they need to conduct a literature review and sift through articles pertaining to the company. This process is very time intensive and requires supervision and direction from the advisor. Also, writers have to augment this secondary data with primary data. For example, case writers often interview employees in order to include personal accounts of issues within the company. This level of research creates an environment of innovative thought, because undergraduates are not limited to the constraints of the classroom. With this freedom, students are only limited by their own desire to learn.

Writing a case requires much more investigation than simply solving a case using theory from a text. Case writers focus on having comprehensive knowledge of a company and a specific problem with which the company is confronted. In this sense, writing a case is much different from many projects that undergraduates typically undertake. This in-depth investigation gives students a much more complete learning experience than a classic project. In preparation for the undergraduates to write a case, it might be helpful for the advisor to draft an "Initial Detailed Teaching Note" for the purpose of guiding the production of the case (Cinnéide, B. Ó., 2006). The students would be able to use the teaching note as a direction for research and writing, thus reducing ambiguity and increasing productivity.

Motivation for completion of the case study is important because of the potential scope of the project. The development of a case can often take several months, so undergraduates need to have individual motivation for independent learning. External motivators might include the final grade, team accountability, expressed deadlines, and the possibility of being published. Additionally, students might feel motivated to complete the project because of the potential real world benefits from the research. Through analyzing and developing solutions to an organizational situation, students can feel rewarded by the real world impact of their research (Forman, H., 2006).

\section{GRADUATE VERSUS UNDERGRADUATE CASE WRITING}

Graduate students will have a much easier time writing case studies than undergraduates. With more realworld experience and superior writing skills, graduate students clearly make prime candidates for case writers. Advisors are likely to be less enthusiastic about working with undergraduate students because of this disparity, but undergraduates can benefit from the case writing experience as much as graduate students. Although graduate students have additional skill sets to draw from to enhance the case study, undergraduates have a tremendous potential to learn through the process.

Writing a case study is a very ambiguous undertaking. The direction of the research can be vague, the statistics and data are often elusive, and the solutions require intensive reflection. Graduate students are better equipped and require less guidance than undergraduates in this process. However, these are the skills that are needed in the workplace, and it is important that undergraduates are also given the opportunity to learn through the case writing method. There are major differences in the type of learning for graduate students and undergraduates. Usually the concepts that undergraduates write about are relatively new to them. This obviously prolongs the process, but can help to solidify the concepts in the undergraduates' minds. Also, having been exposed to case studies on a limited basis can cause undergraduates to be unsure of the structure of the case study. Graduate students have an existing framework that is helpful for building a case study through their experience scholastically and at work. Thus, the benefit for graduate students is primarily a reinforcement of existing concepts. Additionally, having been exposed to numerous case studies, graduate students are much more familiar with the various formats of cases.

Another potential advantage for undergraduate case writers is the limited exposure that they have to case studies. When working closely with an advisor, undergraduates might have more innovative ideas about the methods, research, or structure of a case. Although graduate students have more experience than undergraduates, they would be more prone to relying on that experience without incorporating innovative thought into the case. 
The final outcome of writing a case study is the submission of the case to a publisher. Both graduate students and undergraduates have the same opportunity to publish their work. Although it will likely take undergraduates longer to finish a case, with the help of an advisor they can attain the same quality of work as graduate students.

\section{CONCLUSION}

Although undergraduates have less experience to bring to a case writing project, they come away with a significantly improved grasp of the case concepts. Writing cases involves open-ended learning that is both time consuming and rewarding for undergraduates. This open-ended learning enhances undergraduates' knowledge and enables them to think innovatively. Writing a case is beneficial for undergraduates' development because there are few constraints and students are not limited to a textbook or course guidelines. Undergraduates have a greater challenge writing case studies than graduates because of their lack of experience. While some advisors might not want to work with undergraduates for this reason, it can provide the undergraduates a tremendous learning opportunity. Developing a case enhances undergraduates' professional opportunities previously not available to them, and also helps prepare undergraduates for graduate school. We hope that our experience will motivate other undergraduates to do similar research and write their own case studies to better themselves and to prepare for the business world.

\section{APPENDIX 1}

\section{The Typical Chronological Order of Case Writing}

1. Preparation - Participants brainstorm areas of interest and identify the organization the case will be about. Core concepts are outlined in an Initial Detailed Teaching Note.

2. Research - Participants engage in in-depth research about the topic, the organizations key events, and similar organizations. Also, participants begin writing the background of the case.

3. Analysis - Participants evaluate the data that has been collected and determine the key sections of the case.

4. Writing - Participants extract data from sources and incorporate it into the case.

5. Editing - Participants examine the rough draft to correct grammar, cite sources, find missing data, and strengthen the structure of the case.

6. Submission - Participants can submit the case to various case research associations for review and hopeful approval for publishing.

\section{APPENDIX 2}

\section{The Microsoft Case}

In November of 2005, three students from the University of Washington Bothell (UWB) were encouraged by a professor to form a group to develop a class assignment into a full case study in hopes it would one day be published. The class topic was Management of Organizations, an introductory class for juniors entering the Business program. We did not have a lot of knowledge about the whole process, but we were eager to learn and create the case. The case topic is regarding the organizational structure and strategy of Microsoft Corporation since Microsoft's inception, with special emphasis on the effectiveness of its reorganizations. Although the project began as a class assignment, it continued as an independent study project throughout the rest of our time at the UW.

When our team began the preparation stage, we were unorganized and unsure of what we should be accomplishing as group. The process of writing a case study was foreign and we were hesitant to proceed. Initially, we met frequently as a team to talk about what we wanted to achieve, how we would research and then write the paper, and what we wanted as our end goals. By stating our objectives first it helped everyone know exactly what their role would be throughout the process. Although we did not form an Initial Detailed Teaching Note, our professor was very helpful in guiding our efforts. 
In the next stage we started conducting our research for the project. Our research was accomplished primarily independently and through secondary sources. This allowed everyone to research different sub-topics within the overall topic and enabled us to each understand Microsoft as a whole. We reviewed many articles about Microsoft and organizational structure and strategy in general. The company has a high profile which allowed us to gather a lot of data, including many other independent analyses of the company.

After gathering enough data, we started analyzing it to better understand how the company related to the case topic. We were then able to pick out the most important elements of the company's history to include in the case. Most importantly, we were able to identify the major reorganizations at Microsoft, and to some extent, what effects they had on the organization. We were also able to determine the various life cycles the company entered and left by certain markers in the company's history.

After analyzing the data we began writing the case study. Throughout the process we used a round robin approach to writing. As one person was finished making additions or edits to the existing paper, another would take it for an expressed amount of time. This method of writing worked well for us because it allowed each student to continue to research various parts of the paper. When we first started writing the case study we would meet as an entire group every other week for an update on how the paper was going. This allowed us to ask questions directly to the instructor and team members and allowed us to voice any concerns we had.

Throughout the case's development we were constantly editing everyone's work to improve its quality. The editing process was very time consuming because we were all at different levels of writing ability, and our personal sections did not initially flow together. Throughout our paper writing process the instructor coached us on what we needed to change and what was working for the group. Also, another challenge we faced was eliminating erroneous information. It was sometimes necessary to cut out entire sections of the case in order to make it stronger. As painful as they were, our refinement efforts paid off when we were finally done with the polished version of the case.

We each had individual reasons motivating us to write this case. While we each received credit for a portion of the project, credit was only a small part. Each of us spent quite a bit of time on the project and we saw it as a tool to enhance our ability to excel academically and professionally. Graduate school was a likely option in each of our minds, and we hoped this would prepare us to be accepted into a school. Also, many of the concepts we discussed in the case are easily applicable in other real world scenarios. So by studying them as we have, we are more prepared for the business world. We knew this was a unique opportunity for us as undergraduates, and this motivated us even further. By writing this case we have learned some critical aspects in strategy and different ways by which to identify, shape, and refine the strategy of businesses. In total, it took us over a year to complete the case. This was primarily because it was a spare-time project that initially had no completion date. As the weeks went by, our professor continued encouraging us to keep going.

Initially one of our most significant challenges as a team was the coordination and communication of all the members. It was difficult to divide up responsibilities at first with so many different aspects of Microsoft to examine. However, we were able to work past this by sharing research. Throughout the writing of the project we had evaluations of team members and of the team's progress. This helped gauge where we were as individuals and what still needed to be accomplished in the case study. Presently, the case is being reviewed by the North American Case Research Association. They asked us to edit a few portions of the case, and we are waiting now to hear back from them soon.

As undergraduate case writers, we have been privileged to work on this project and look forward to being a part of another case writing team as graduate students. 


\section{REFERENCES}

1. Cinnéide, B. Ó. (2006). Developing and testing student oriented case studies. Journal of European Industrial Training. Emerald Group Publishing Limited: Bradford, 30(5), 349-364.

2. David, F. (2003). Strategic Management Case Writing: Suggestions After 20 Years of Experience. S.A.M. Advanced Management Journal, 68(3), 36-42.

3. Forman, H. (2006). Participative Case Studies: Integrating Case Writing and a Traditional Case Study Approach in a Marketing Context. Journal of Marketing Education. Sage Publications: Boulder, 28(2), 106-113.

4. Leenders, M., Erskine, J. (1978). Case Research: The Case Writing Process, 2nd ed.,The University of Western Ontario: Ontario.

5. Mostart, P., Sudzina, M. (1996). Undergraduate Case Method Teaching: Pedagogical Assumptions of Teacher Educators. Annual Meeting of the Association of Teachers Educators. St. Louis, MO.

6. Naumes, W., Naumes, M. (1999). The Art and Craft of Case Writing. Sage Publications Inc: Thousand Oaks, CA.

\section{NOTES}

